Artículo de reflexión

Cuestiones de Filosofía

ISSN: 0123-50-95

E-ISSN: $2389-9441$

Vol. 5 - No 24 Enero- junio, año 2019

pp. $145-170$

\title{
Planejamento do ensino de Filosofia: entre a normatividade e a prática pedagógica
}

\section{Planning for philosophy teaching: between normativity and the pedagogical practice}

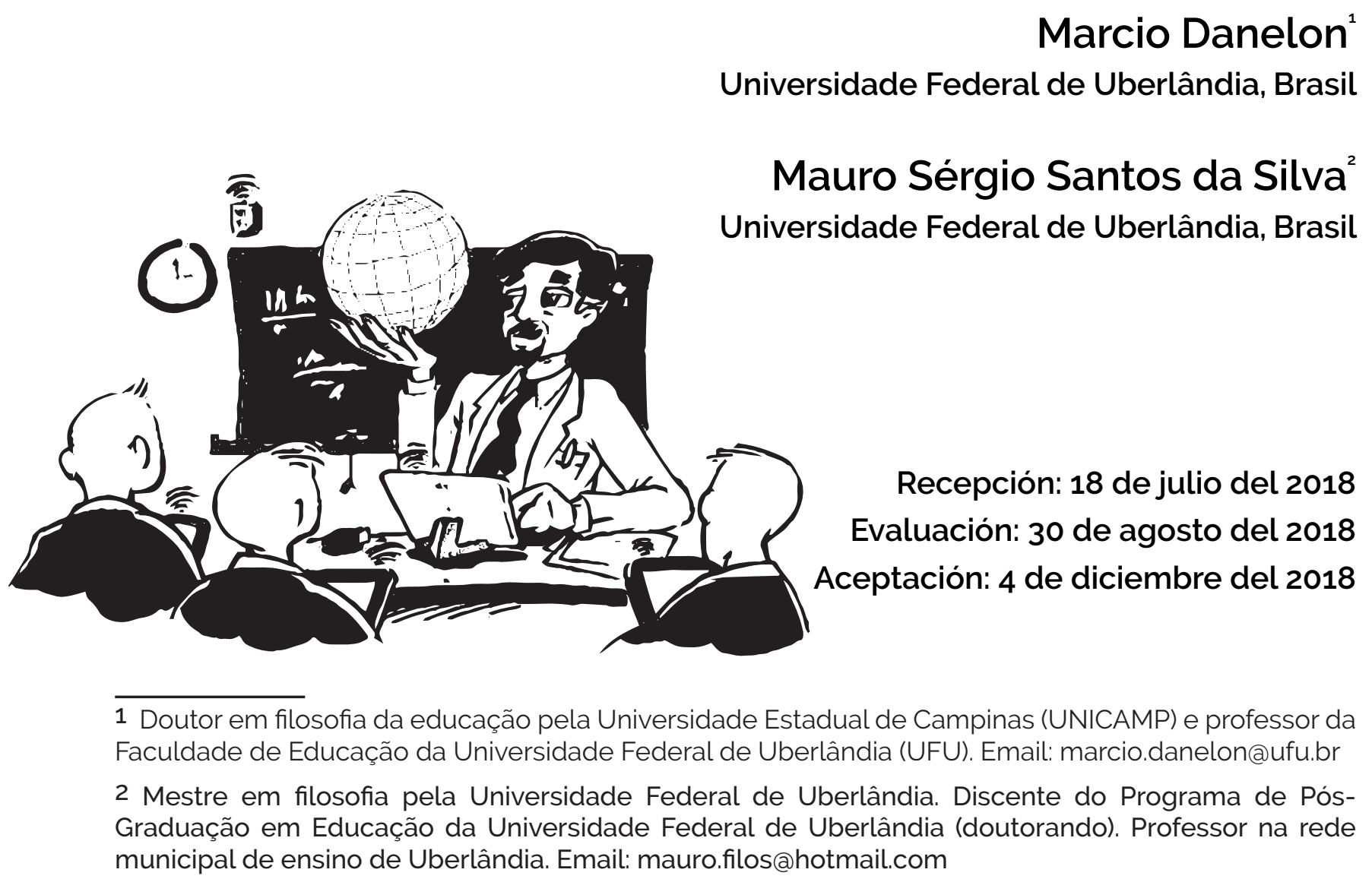




\section{Resumo:}

Este artigo tem por objetivo investigar as relações e interfaces entre as políticas públicas para o ensino de Filosofia e as práticas do professor de Filosofia nas escolas de ensino médio. Objetivamos, notadamente, analisar três documentos reguladores do ensino de Filosofia, a saber, as Orientações Curriculares Nacionais de Filosofia (Ministério da Educação), o Currículo Básico Comum de Filosofia (Secretaria de Estado de Educação de Minas Gerais) e as Diretrizes Gerais da Disciplina de Filosofia (Universidade Federal de Uberlândia), observando as influências desses documentos no plano de ensino dos professores de filosofia das escolas públicas da região de Uberlândia/Minas Gerais. Assim, queremos saber em qual instância esses documentos oficiais administram as práticas pedagógicas dos professores de filosofia. Para isso, a metodologia empregada foi a pesquisa bibliográfica e documental que nos permitiu chegar a conclusão de que há um excesso de documentos reguladores do ensino de filosofia no Estado de Minas Gerais.

Palavras-chave: Educação média; Ensino de filosofia; Escola; Políticas públicas na educação.

\section{Abstract:}

This article aims to research the relationships and interfaces between public politics for philosophy teaching and the practices of the teacher of philosophy in high school institutions. We target, notably, to analyze the three regulatory documents for philosophy teaching, as far as we know, the National Curricular Orientations of Philosophy (Ministry of Education), the Common Basic Curriculum of Philosophy (Education Office of Minas Gerais) and the General Command of the Discipline of Philosophy (Federal University of Uberlandia). By watching the influence of these documents in the field of teaching of the teachers of philosophy in the public schools within the region of Uberlandia (Minas Gerais). Thus, we want to know in which instance of these official documents is managed the pedagogical practices of the teachers of philosophy. The employed methodology was a bibliographic and documental revision that allowed us to achieve a conclusion that there is an excess of regulatory documents for teaching philosophy in the state of Minas Gerais.

Key-word: high school, philosophy teaching, school, public policies in education. 


\section{Planeación de la enseñanza de Filosofia: entre la normatividad y la práctica pedagógica}

\section{Resumen:}

Este artículo tiene por objetivo investigar las relaciones e interfaces entre las políticas públicas para la enseñanza de Filosofía y las prácticas del profesor de Filosofía en las escuelas del bachillerato. Objetivamos, notablemente, analizar tres documentos reguladores de la enseñanza de Filosofía, a saber, las Orientaciones Curriculares Nacionales de Filosofía (Ministerio de Educación), el Currículo Básico Común de Filosofía (Secretaría de Estado de Educación de Minas Gerais) y las Directrices Generales de las Disciplina de Filosofía (Universidad Federal de Uberlândia), observando las influencias de esos documentos en el plano de enseñanza de los profesores de filosofía de las escuelas públicas de la región de Uberlândia (Minas Gerais). Así, queremos saber en cuál instancia esos documentos oficiales administran las prácticas pedagógicas de los profesores de filosofía. Para eso, la metodología empleada fue la revisión bibliográfica y documental que nos permitió llegar a conclusión de que hay un exceso de documentos reguladores de la enseñanza de la filosofía en el Estado de Minas Gerais.

Palabras clave: Educación media, enseñanza de la filosofía, escuela, políticas públicas en educación.

\section{Planification de l'enseignement de Philosophie : entre la normativité et la pratique pédagogique}

\section{Résumé}

Cet article a comme but principale, investiguer les relations et interfaces parmi les politiques publiques pour l'enseignement de Philosophie et les pratiques de l'enseignant de philosophie aux écoles secondaires. Nous objectivons de pouvoir analiser trois documents régulateurs de l'enseignement de Philosophie, c'est-à-dire: Les Orientations Curriculaires Nationales de Philosophie (Ministère d'Éducation), le Curriculum Basique Commun de Philosophie (Secrétariat d'État d'Éducation de Minas Gerais) et les Directrices générales de des Disciplines de Philosophie (Université Fédéral d'Uberlândia), en regardant les influences de ceux documents dans l'environnement d'enseignement des enseignants de philosophie des écoles publiques de la région d'Uberlândia (Minas Gerais). Donc, nous voulons savoir dans quel séjour ces documents officiels administrent les pratiques pédagogiques des professeurs de philosophie. Pour y arriver, la méthodologie utilisée a été la révision bibliographique et documentaire, ces outils nous ont permis de conclure qu'il y a un excès de documents régulateurs de l'enseignement dans l'État de Minas Gerais.

Mots-clés : Enseignement secondaire, enseignement de la philosophie, école, politiques publiques en matière d'éducation. 


\section{1-) Situando um problema}

A prática do professor de filosofia no Brasil, assim como em outros paises, é norteada por documentos e projetos pensados e produzidos em diversos niveis institucionais. Tratam-se das chamadas propostas, orientações ou diretrizes curriculares para a disciplina de Filosofia ministrada, sobretudo, no ensino médio, que, além de apresentarem uma concepção de Filosofia com sua justificativa na formação dos jovens, de discutirem o lugar da Filosofia nos currículos do ensino médio, de elencarem objetivos e discutirem os tipos e formas de material didático, de refletir e, em alguns casos, propor formas de avaliação em Filosofia, estes documentos estipulam conteúdos de filosofia a serem ensinados pelo professor de filosofia.

Nesta sorte, o problema norteador deste texto centra-se na emergência da pergunta pela identidade do professor de Filosofia. Em que consiste a sua prática pedagógica em uma sala de aula definitivamente administrada por diferentes documentos oficiais reguladores? Neste caso, especificamente, analisaremos a atividade do professor de Filosofia que desempenha a docência em escolas ligadas à Superintendência Regional de Ensino de Uberlândia (SRE/MG), e que se depara, necessariamente, com pelo menos três documentos normativos de sua prática pedagógica e que definem conteúdos de filosofia a serem ensinados nas escolas de nivel médio, a saber: As Orientações Curriculares Nacionais de Filosofia (documento de âmbito Federal e produzido pelo Ministério da Educação); Currículo Básico Comum de Filosofia (documento de âmbito estadual e produzido pela Secretaria de Estado da Educação de Minas Gerais) e as Diretrizes Gerais da disciplina de Filosofia para o processo seletivo da Universidade Federal de Uberlândia (documento de âmbito regional e produzido pela Universidade Federal de Uberlândia).

Como são três documentos distintos, conforme veremos, e três documentos balizadores de avaliação a que o aluno do ensino médio estará submetido (Exame Nacional do Ensino Médio - ENEM - cujo documento balizador desta avaliação é As Orientações Curriculares Nacionais de Filosofia; o vestibular da Universidade Federal de Uberlândia, cujo documento balizador dessa avaliação é as Diretrizes Gerais da disciplina de Filosofia para o processo seletivo da Universidade Federal de Uberlândia; e Programa de Avaliação da Educação Básica - PROEB/Minas Gerais - cujo documento 
balizador é Currículo Básico Comum de Filosofia), o problema que levantamos é quanto à forma de organização do plano de ensino do professor de filosofia. Em qual documento ele se orientará na elaboração de seu plano de ensino? Como atender, com conteúdos específicos, a três avaliações distintas que seus alunos se submeterão? Quais critérios o professor adotará na seleção dos conteúdos em seu plano de ensino?

\section{2-) Documentos normatizadores da disciplina de filosofia no ensino médio}

\section{1-) Orientações Curriculares Nacionais do Ensino Médio - Ciências Humanas e suas Tecnologias}

As Orientações Curriculares do Ensino Médio - Ciências Humanas e suas Tecnologias - de Filosofia (doravante OCN/Filosofia), foram produzida em 2006 pela Secretaria de Educação Básica do Ministério da Educação, num ambiente em que a obrigatoriedade da disciplina de Filosofia no ensino médio e o modelo do Enem como forma de ingresso no ensino superior das Universidades Federais ainda se configuravam enquanto projetos. Tem como objetivo fundante "contribuir para o diálogo entre professor e escola sobre a prática docente" (OCN/Filosofia, 2008, p. 05). Trata-se de um documento que revisita os Parâmetros Curriculares Nacionais do Ensino Médio (doravante PCN/Filosofia de 1999). Particularmente, destacamos as reflexões em torno de uma definição de Filosofia, da justificação do caráter formativo inerente a ela, dos objetivos da disciplina de Filosofia no ensino médio e, enfim, das competências ${ }^{3}$ e habilidades desejadas ao educando com essa disciplina. Inova, de outra forma, ao trazer uma discussão, espinhosa, em torno da metodologia para o ensino de Filosofia.

Quanto ao tópico conteúdos de Filosofia (objeto de nossa reflexão neste texto), este documento, à luz do objetivo das $\mathrm{OCN}$, de se constituir numa alternativa orientadora da prática docente em sala de aula, emerge enquanto cultura material que pode ser utilizada pelo professor na elaboração do planejamento de sua disciplina, configurando num esforço de aproximação das políticas pública de educação com

\footnotetext{
3 A despeito de todas as oscilações semânticas do termo, das muitas diatribes educacionais e políticas, que conflagraram as concepções curriculares do final do século passado e na primeira década do século atual, o conceito 'competência' ingressou, progressivamente, nos discursos sobre currículo. Promovido por agências e uniões internacionais, o termo firmou-se como o novo paradigma curricular de muitos sistemas de educação (CHIZZOTTI, 2012, p. 432).
} 
o chão da escola. Assim, a eleição de conteúdos de Filosofia presentes nas OCN/ Filosofia circunscreve nesse ideário de ser material orientador para o professor. A eleição de conteúdos de Filosofia presente nas OCN/Filosofia não apresenta a mesma extensão e densidade teórica e reflexiva dos PCN+/Filosofia. Ao contrário, é mais sintético, constituindo-se numa lista de trinta itens possiveis de serem desenvolvidos pelo professor de Filosofia em seu plano de ensino:

Filosofia e conhecimento; Filosofia e ciência; definição de Filosofia;

validade e verdade; proposição e argumento;

falácias não formais; reconhecimento de argumentos; conteúdo e forma;

quadro de oposições entre proposições categóricas; inferências imediatas em contexto categórico; conteúdo existencial e proposições categóricas; tabelas de verdade; cálculo proposicional;

filosofia pré-socrática; uno e múltiplo; movimento e realidade; teoria das ideias em Platão; conhecimento e opinião; aparência e realidade; a política antiga; a República de Platão; a Política de Aristóteles;

a ética antiga; Platão, Aristóteles e filósofos helenistas;

conceitos centrais da metafísica aristotélica; a teoria da ciência aristotélica;

verdade, justificação e ceticismo;

o problema dos universais; os transcendentais;

tempo e eternidade; conhecimento humano e conhecimento divino;

teoria do conhecimento e do juizo em Tomás de Aquino; 
a teoria das virtudes no período medieval;

provas da existência de Deus; argumentos ontológico, cosmológico, teleológico;

teoria do conhecimento nos modernos; verdade e evidência; idéias; causalidade; indução; método;

vontade divina e liberdade humana;

teorias do sujeito na filosofia moderna;

o contratualismo;

razão e entendimento; razão e sensibilidade; intuição e conceito;

éticas do dever; fundamentações da moral; autonomia do sujeito;

idealismo alemão; filosofias da história;

razão e vontade; o belo e o sublime na Filosofia alemã;

crítica à metafísica na contemporaneidade; Nietzsche; Wittgenstein; Heidegger;

fenomenologia; existencialismo;

Filosofia analítica; Frege, Russell e Wittgenstein; o Círculo de Viena;

marxismo e Escola de Frankfurt;

epistemologias contemporâneas; Filosofia da ciência; o problema da demarcação entre ciência e metafísica; Filosofia francesa contemporânea; Foucault; Deleuze.

Neste documento, os motivos justificadores para tal elenco de conteúdo "[...] tem por referência os temas trabalhados no currículo mínimo dos cursos de graduação em Filosofia e cobrados como itens de avaliação dos egressos desses cursos, ou seja, os professores de Filosofia para o ensino médio". (OCN/Filosofia, 2006, p. 34). 
Em outras palavras, a concepção de prática docente do professor inerente a OCN/ Filosofia defende um paralelismo intrínseco entre os conteúdos de formação (ensino superior) e os conteúdos de ensino e atividade profissional (ensino médio). Emerge, neste documento, de fato, uma visão de que o ensino médio se constitui num espelho do ensino superior, ou seja, uma simetria entre os conteúdos da licenciatura em Filosofia e a formação em ensino médio.

A OCN/Filosofia (2006, p. 37) defende, reiteradamente, a necessidade de "[...] manter a centralidade do texto filosófico (primário de preferência)", essa simetria é reforçada pelo uso comum do material bibliográfico, a saber, os textos clássicos da Filosofia. A OCN/Filosofia peca, então, por não qualificar os conteúdos de Filosofia às especificidades de idade, de interesse e de objetivos que há na formação universitária e na formação básica. Apesar de apoiar uso de material distinto nas aulas de Filosofia ${ }^{4}$ no ensino médio a OCN/Filosofia, ao justificar a formação acadêmica do professor como critério para a eleição de conteúdos de Filosofia no ensino médio e ao propor a centralidade nos clássicos de Filosofia como material didático, entende, de fato, que o ensino de Filosofia em nivel médio é uma versão simplificada ou reduzida do ensino de Filosofia em nivel superior, apesar de fazer essa ressalva ${ }^{5}$.

A lista de conteúdos propostos na OCN/Filosofia segue a proposta de um ensino de Filosofia historiográfico, centrado no texto clássico da Filosofia. Porém, um olhar mais atendo a esses argumentos da centralidade na história da Filosofia leva-nos a dúvidas na fé apregoada no ensino de Filosofia centrado na história da Filosofia tal qual é apresentada neste documento. Observando a lista de conteúdos propostos na OCN/Filosofia não é possivel perceber uma estrutura histórica para o leque a conteúdos propostos (OCN/Filosofia, 2006, p. 27).

Há, de fato, uma defesa do eixo historiográfico no ensino de Filosofia, mas os conteúdos propostos na OCN/Filosofia não formalizam uma concepção de ensino de Filosofia centrado no eixo da história da Filosofia. Os conteúdos propostos na OCN/Filosofia que, conforme reza o documento, devem inspirar o professor na elaboração de seu plano de trabalho, parecem muito mais uma miscelânea de

4 Garantidas as condições teóricas já citadas, é desejável e prazerosa a utilização de dinâmicas de grupo, recursos audiovisuais, dramatizações, apresentação de filmes, trabalhos sobre outras formas de textos". (OCN/Filosofia, 2006, p. 38)

5 [...] evitar posições extremadas, que, por exemplo, (i) nos fariam transpor para aquele nível de ensino (médio) uma versão reduzida do currículo de graduação.... (OCN/Filosofia, 2006, p. 38) 
temas/problemas/assuntos que, necessariamente, encontrariam moradia na história da Filosofia do que uma proposta clara de um ensino de Filosofia que tem na História da Filosofia o seu eixo.

\section{2-) Currículo Básico Comum/Filosofia do Estado de Minas Gerais}

O documento Currículo Básico Comum/Filosofia (doravante CBC/Filosofia) é um documento oficial produzido pela Secretaria de Estado de Educação de Minas Gerais. Os CBCs de diferentes disciplinas tanto do ensino fundamental quanto do ensino médio objetivam

[...] Estabelecer os conhecimentos, as habilidades e as competências a serem adquiridos pelos alunos na educação básica, bem como as metas a serem alcançadas pelo professor a cada ano, é uma condição indispensável para o sucesso de todo sistema escolar que pretenda oferecer serviços educacionais de qualidade à população. A definição dos conteúdos básicos comuns (CBC) para os anos finais do ensino fundamental e para o ensino médio constitui um passo importante no sentido de tornar a rede estadual de ensino de Minas num sistema de alto desempenho. (CBC, s/d, p. og: apresentação da Secretária de Estado de Educação de Minas Gerais)

Trata-se de um documento norteador da prática pedagógica do professor, uma vez que será tomado como base para as avaliações de desempenho dos professores e de aprendizagem dos alunos. Sobre isso, destaca-se que o Currículo Básico Comum estabelece objetivos e metas a serem atingidos pelos professores, bem como propõe conteúdos para cada disciplina do ensino fundamental e médio. Apresentase, de fato, enquanto um documento mais incisivo e diretivo na prática do professor Todos esses elementos - conteúdos, metas e objetivos - serão objetos de avaliação promovida pela Secretaria de Estado de Educação de Minas Gerais (CBC, s/d, p.og).

O CBC/Filosofia parte e dialoga comos Parâmetros Curriculares Nacionais/Filosofia e as Orientações Curriculares Nacionais/Filosofia. Apresenta, neste caso, pontos de confluência bastante específicos, dentre eles, o destaque para a importância do uso de texto filosófico em sala de aula, a necessidade de formação filosófica do professor de Filosofia, a defesa no desenvolvimento das competências da argumentação, escrita e reflexão. No CBC/Filosofia, por outro lado, o objetivo da 
disciplina de Filosofia no ensino médio constitui na "[...] ampliação do horizonte cultural do estudante, que tomará conhecimento de um aspecto fundamental da tradição ocidental, ou seja, o legado dos grandes pensadores". (CBC, s/d, p. 11), não fazendo menção, portanto, ao ideário de formação cidadã ao estudante do ensino médio.

A proposta de conteúdos de Filosofia para o ensino médio, exposta no CBC/Filosofia, diferentemente das OCN/Filosofia, determina que o conteúdo curricular apareça organizado a partir de temas, pois acredita "[...] que essa estratégia pode facilitar a tarefa de retomada da tradição de uma maneira indagadora e adequada ao seu público alvo". (CBC/Filosofia, s/d, p. 12) A despeito dessa diferença, o CBC/Filosofia destaca a importância da História da Filosofia, na medida em que defende que os temas filosóficos propostos enquanto conteúdos sejam tratados historicamente, abordados a partir da história da Filosofia (CBC/Filosofia, s/d, p. 13). Os conteúdos de Filosofia no $\mathrm{CBC} /$ Filosofia são construídos da seguinte forma:

-Campos de Investigação: Ser Humano; Agir e Poder; Conhecer.

-Temas: são identificados no interior de cada campo de investigação e se constituem propriamente em objetos de tratamento e reflexão filosófica na disciplina de Filosofia no ensino médio. (CBC/Filosofia, s/d, p. 14)

Conceitos: para cada tema de cada campo de investigação são associados conceitos, que se constituem em instrumentos de pensamento que definem e delimitam o tema. (CBC/Filosofia, s/d, p. 14)

Isso posto, o CBC/Filosofia, apresenta da seguinte forma a lista de conteúdos de Filosofia para subsidiar o trabalho do professor: 


\section{Ser humano}

1.1. Natureza e cultura

1.2. Corpo e psiquismo

\section{Agir e poder}

2.1. Os valores

a. Ser e dever ser

b. Universalidade e relatividade dos valores

2.2. Liberdade e determinismo

2.3. Indivíduo e comunidade

a. Conflito

b. Lei e justiça

\section{Conhecer}

3.1. Verdade e validade

3.2. Tipos de conhecimento

a. A emergência da filosofia

b. Filosofia e outros saberes

3.3. A racionalidade científica
a. Teoria e experiência
b. Objetividade e Verdade

O documento expõe duas justificativas para a escolha dos temas propostos: "a prática já sedimentada no ensino de Filosofia atualmente em curso, e que se encontra de certo modo refletida nas diversas publicações de nivel introdutório hoje existentes [...] a necessidade de renovação dessa prática, introduzindo temas relevantes atual e, principalmente, indicando, na Bibliografia, os textos filosóficos vinculados aos temas propostos" (CBC/Filosofia, s/d, p. 14). Enquanto as OCN/Filosofia tomavam, conforme vimos, a formação superior em Filosofia do professor como critério para 
a escolha dos conteúdos de Filosofia propostos, numa tentativa de assimetria entre a formação e a prática profissional, o CBC/Filosofia toma, em essência, a produção literária de Filosofia disponivel no mercado (livros didáticos, introdutórios e clássicos de Filosofia, além de coleções temáticas) como critério para construir uma proposta de conteúdos de Filosofia para o ensino médio.

Observemos, por fim, que os conteúdos propostos estão bastante delimitados e organicamente organizados. Sobre isso destaquemos, (i) que a própria estrutura do conteúdo sugerido no CBC/Filosofia para a disciplina de Filosofia no ensino médio tem o formato de um plano de trabalho para o professor, com a definição de grandes áreas, de temas e subtemas; (ii) que o documento elenca uma série de questões/ problemas "relacionadas aos temas que podem servir de 'porta de entrada' para 0 tratamento" (CBC/Filosofia, s/d, p. 15) filosófico do professor durante as aulas; (iii) que apresenta uma extensa lista de textos que podem ser utilizados como material didático pelo professor (CBC/Filosofia, s/d, p. 26-37); (iv) que, por fim estabelece princípios norteadores para a prática do professor e parâmetros fundamentais para orientar o debate em torno da avaliação em Filosofia (CBC/Filosofia s/d, p.1516). Assim, este documento da Secretaria de Estado de Educação de Minas Gerais praticamente se constitui num plano de curso para o professor aplicar em suas aulas de Filosofia no ensino médio.

\section{3-) Diretrizes Gerais da Disciplina de Filosofia: Vestibular/Universidade Federal de Uberlândia}

A Universidade Federal de Uberlândia, através de sua Diretoria de Processo Seletivo, divulga, em todo processo seletivo de ingresso no ensino superior da universidade, o documento intitulado "Diretrizes Gerais" de cada disciplina que compõe as provas de ingresso. Esse documento é elaborado nos Departamentos de origem das disciplinas presentes no processo seletivo. As Diretrizes Gerais da disciplina de Filosofia (doravante Diretrizes Gerais/UFU) foram elaboradas pelo Instituto de Filosofia da Universidade Federal de Uberlândia, ouvido os professores de Filosofia da rede pública e privada de ensino médio de Uberlândia e região, ligados a Superintendência Regional de Ensino de Uberlândia(SER/MG). 
Para as Diretrizes Gerais/UFU, o objetivo da Filosofia no ensino médio é possibilitar ao estudante acesso ao legado cultural da Filosofia, conforme lemos nesse documento: "reabilitação da filosofia tem como objetivo contribuir com a restituição do rigor do pensamento e com a formação de um repertório cultural mais critico, que saliente momentos marcantes do pensamento ocidental e das instituições construidas no seu contexto". (Diretrizes Gerais/UFU, s/d, p. 01) O repertório cultural e a compreensão dos momentos marcantes do pensamento ocidental, enquanto objetivos da disciplina de Filosofia no ensino médio, reflete uma concepção historicista de ensino de Filosofia, uma vez que o seu legado cultural tem na História da Filosofia seu lugar privilegiado. Compreende-se, então, o caráter conteudista e informativo dos conteúdos de Filosofia como premissa para uma formação do "espírito crítico" do aluno (Diretrizes Gerais/UFU, s/d, p. 01).

De acordo com as Diretrizes Gerais/UFU, os conteúdos de Filosofia deverão ser abordos em duas seções: (i) o conhecimento (lógica, metafísica, teologia e teoria do conhecimento) e (ii) a ação (ética e política). Cada uma dessas seções está dividida, por sua vez, em eixos temáticos. Nesse caso, a seção do Conhecimento está subdividida em três eixos temáticos e a seção da Ação, em dois eixos temáticos. É nos eixos temáticos que As Diretrizes Gerais/UFU revelam uma concepção historicista de ensino de Filosofia, na medida em que cada eixo demarca um período histórico da Filosofia e elenca, de forma cronológica, os conteúdos programáticos do eixo temático, conforme segue abaixo: 


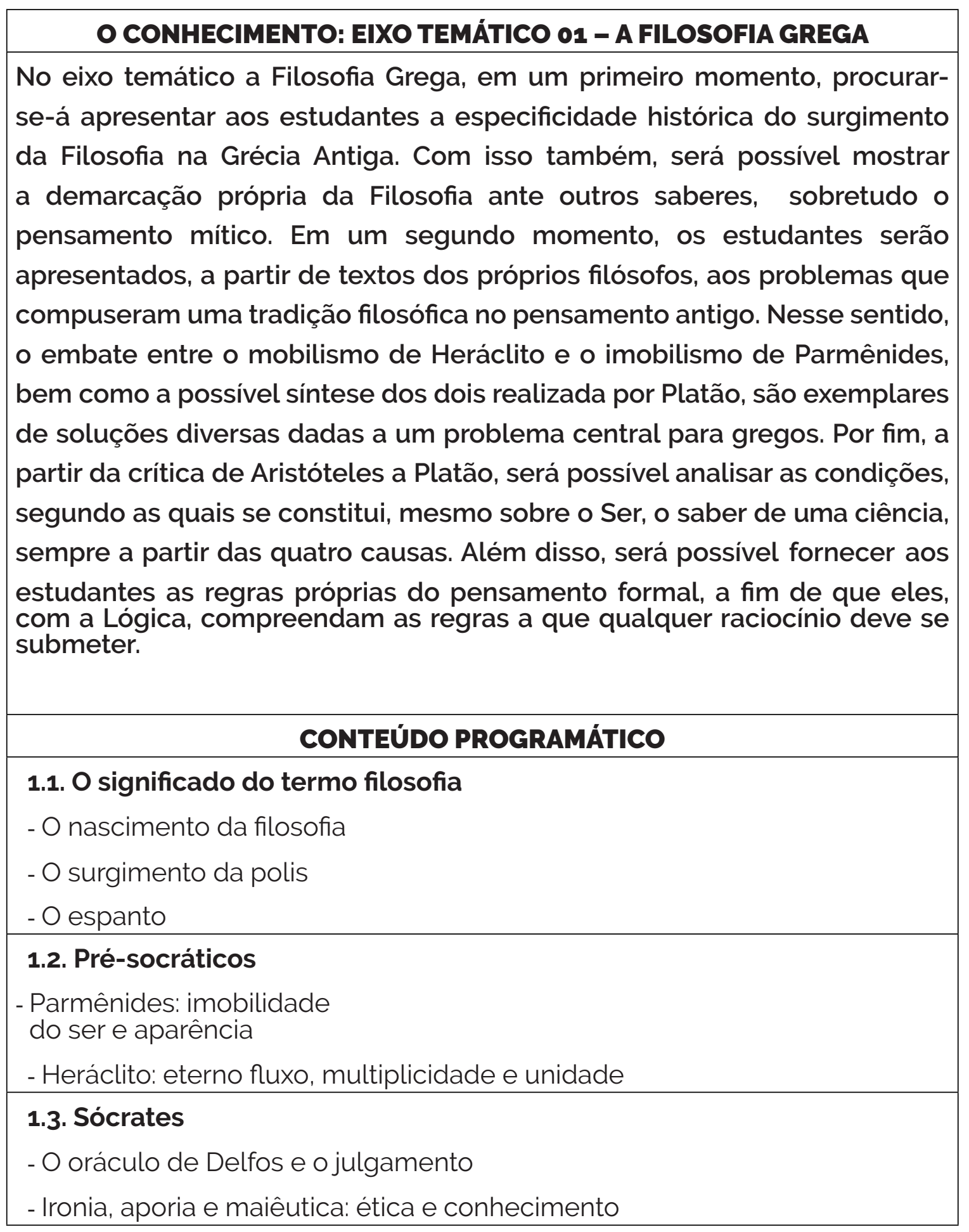




\subsection{Platão}

- A alegoria da caverna

- A relação entre o

sensivel e o inteligivel

- Reminiscência e conhecimento

- O ideal da política: o rei filósofo

1.5. Aristóteles
- Metafísica
- As cate- glorias:
- substân-
- cia e aci-
- dentes
- Teoria das quatro
causas
- Noções de lógica
- Proposição: verdade e falsidade
- O silogismo: termos, pre-
missas e Validade

Na sequência da seção Conhecimento das Diretrizes Gerais/UFU, o eixo temático 02 trata da Teoria do Conhecimento no Período Medieval, com o conteúdo programático destacando a patrística, a escolástica e Tomás de Aquino. E o eixo temático 03 aborda a Teoria do Conhecimento na Modernidade, com o conteúdo programático destacando Descartes, Hume e Kant. Na seção da Ação, temos o eixo temático 04, que trata da Política, e nos conteúdos programáticos destacam-se Maquiavel, Hobbes, Locke, Rousseau, Hegel e Marx. Finalmente ainda na seção da Ação, os conteúdos de Filosofia das Diretrizes Gerais/UFU se encerram com o eixo temático 05, que trata da Ética, com o conteúdo programático para Aristóteles, Kant, Nietzsche e Sartre. Todos esses eixos temáticos seguem o mesmo modelo acima reproduzido. 
As Diretrizes Gerais/UFU definem, de forma bastante pontual, conteúdos especíicos de Filosofia que tem na História da Filosofia seu eixo. Cabe também salientar que acompanha os conteúdos programáticos, em uma coluna à direita do documento, com o título de "Nivel de exigência", uma espécie de roteiro de ensino para o professor e de estudo para o aluno do ensino médio. Nesta feita, salientamos que o documento Diretrizes Gerais/Filosofia tem, tal qual o documento CBC/Filosofia, o formato de um plano de ensino que pode ser, via de regra, transposto simetricamente para a sala de aula do ensino médio.

\section{3-) Os documentos reguladores e o planejamento do ensino de filosofia nas escolas estaduais da superintendência regional de ensino de uberlândia (sre- mg)}

Até aqui, fizemos uma análise dos três documentos que apresentam propostas de conteúdos e abordagem de Filosofia para subsidiar o professor na elaboração de seu plano de trabalho. Cada proposta tem uma abrangência territorial - do regional ao nacional - e uma visada singular do papel da Filosofia no ensino médio - que vai, por sua vez, da socialização do legado cultural da Filosofia até seu papel eminentemente formador do educando para o exercício da cidadania, passando pela aquisição de competências e habilidades da percepção, problematização, reflexão, conceituação e argumentação.

Os três documentos se diferenciam notadamente no papel e finalidade da Filosofia no ensino médio, na concepção de ensino de Filosofia, no tipo de abordagem e nas sugestões de conteúdos. Apesar de divergirem entre si, são realidades presentes na escola e estão diante do professor. Assim, na elaboração do plano de trabalho, esses três documentos emergem como norteadores para a prática do professor de Filosofia. Nesta direção, analisaremos, a seguir, a influência destes na produção dos planos de ensino ${ }^{6}$ dos professores de filosofia de escolas estaduais da Superintendência Regional de Ensino de Uberlândia (SRE-MG)'.

6 Foram estimulados a contribuir com o presente estudo 30 (trinta) professores de filosofia que atuam em escolas públicas e privadas de municipios pertencentes à microrregião do Triângulo Mineiro, solicitando a disponibilização de seus respectivos planejamentos ou planos anuais. Obtivemos dez (10) devolutivas que se constituem, porquanto, no objeto desta análise.

7 A Superintendência Regional de Ensino de Uberlândia possui 31 (trinta e uma) escolas estaduais com ensino médio e, portanto, o ensino de filosofia, conforme: http://sreuberlandia.educacao.mg.gov.

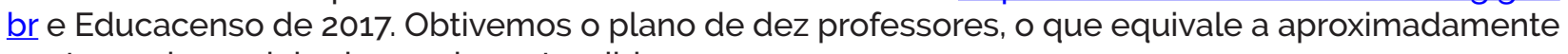
um terço do modelo de escola pretendido. 
A partir da leitura e análise dos planos de ensino colhidos discorreremos acerca do tipo de abordagem adotada e da influência, nos mesmos, de postulados constantes das Orientações Curriculares Nacionais para o Ensino de Filosofia (OCN/Filosofia), do Currículo Básico Comum para o Ensino de Filosofia (CBC/Filosofia) em Minas Gerais e das Diretrizes Gerais da Filosofia do Vestibular da Universidade Federal e Uberlândia (Diretrizes Gerais/UFU).

\section{1-) Planos de Ensino de Filosofia na Superintendência Regional de Ensino de Uberlândia- MG}

Vejamos, nos quadros, a seguir, elementos exarados da leitura e análise dos planos de ensino de professore de filosofia em escolas de ensino médio da Superintendência Regional de Ensino de Uberlândia. No primeiro quadro, destacamos a presença dos três documentos nos mesmos. No outro, transpomos a seleção e organização dos conteúdos.

Quadro 01. A presença dos documentos reguladores atinentes ao ensino de filosofia nos 10 (dez) planos analisados por este estudo.

\begin{tabular}{|l|l|l|l|l|l|l|}
\hline Planos & $\begin{array}{l}\text { Estrutura do } \\
\text { planejamento } \\
\text { abordagem } \\
\text { da seleção } \\
\text { e/ou } \\
\text { organização } \\
\text { de } \\
\text { conteúdos }\end{array}$ & $\begin{array}{l}\text { Citação } \\
\text { direta ou } \\
\text { indireta } \\
\text { das } \\
\text { OCN- } \\
\text { Filosofia }\end{array}$ & $\begin{array}{l}\text { Citação } \\
\text { direta ou } \\
\text { indireta } \\
\text { do CBC- } \\
\text { Filosofia } \\
\text { (MG) }\end{array}$ & $\begin{array}{l}\text { Citação } \\
\text { direta ou } \\
\text { indireta das } \\
\text { Diretrizes } \\
\text { para a } \\
\text { Filosofia do } \\
\text { vestibular } \\
\text { da UFU. }\end{array}$ & $\begin{array}{l}\text { Documento } \\
\text { predominante na } \\
\text { organização e/ } \\
\text { ou seleção dos } \\
\text { conteúdos }\end{array}$ \\
\hline $\begin{array}{l}\text { Plano } \\
\text { O1 }\end{array}$ & $\begin{array}{l}\text { Eixos } \\
\text { Temáticos }\end{array}$ & Histórica & Sim & Sim & Não & Diretrizes Gerais/ \\
U2
\end{tabular}




\begin{tabular}{|c|c|c|c|c|c|c|}
\hline $\begin{array}{l}\text { Plano } \\
04\end{array}$ & $\begin{array}{l}\text { Eixos } \\
\text { Temáticos }\end{array}$ & Histórica & Não & Sim & Não & $\begin{array}{l}\text { Diretrizes Gerais/ } \\
\text { UFU }\end{array}$ \\
\hline $\begin{array}{l}\text { Plano } \\
05\end{array}$ & $\begin{array}{l}\text { Eixos } \\
\text { Temáticos }\end{array}$ & Histórica & Não & Sim & Não & $\begin{array}{l}\text { Diretrizes Gerais/ } \\
\text { UFU }\end{array}$ \\
\hline $\begin{array}{l}\text { Plano } \\
06\end{array}$ & $\begin{array}{l}\text { Eixos } \\
\text { Temáticos }\end{array}$ & Histórica & Sim & Sim & Não & $\begin{array}{l}\text { Diretrizes Gerais/ } \\
\text { UFU }\end{array}$ \\
\hline $\begin{array}{l}\text { Plano } \\
07\end{array}$ & $\begin{array}{l}\text { Eixos } \\
\text { Temáticos }\end{array}$ & Histórica & Sim & Sim & Não & $\begin{array}{l}\text { Diretrizes Gerais/ } \\
\text { UFU }\end{array}$ \\
\hline $\begin{array}{l}\text { Plano } \\
08\end{array}$ & $\begin{array}{l}\text { Eixos } \\
\text { Temáticos } \\
\end{array}$ & Histórica & Não & $\operatorname{Sim}$ & Não & $\begin{array}{l}\text { Diretrizes Gerais/ } \\
\text { UFU }\end{array}$ \\
\hline $\begin{array}{l}\text { Plano } \\
\text { og }\end{array}$ & $\begin{array}{l}\text { História da } \\
\text { Filosofia }\end{array}$ & Histórica & Sim & $\operatorname{Sim}$ & Não & $\begin{array}{l}\text { Diretrizes Gerais/ } \\
\text { UFU }\end{array}$ \\
\hline $\begin{array}{l}\text { Plano } \\
10\end{array}$ & Temas & $\begin{array}{l}\text { Temática } \\
\text { com leitura } \\
\text { de textos } \\
\text { filosóficos }\end{array}$ & Não & Não & Não & $\begin{array}{l}\text { Orientações } \\
\text { Nacionais } \\
\text { Curriculares }\end{array}$ \\
\hline
\end{tabular}

\section{Quadro 02. A seleção e a organização dos conteúdos de Filosofia presentes nos 10 (dez) planos anuais analisados para os 3 (três) anos do Ensino Médio.}

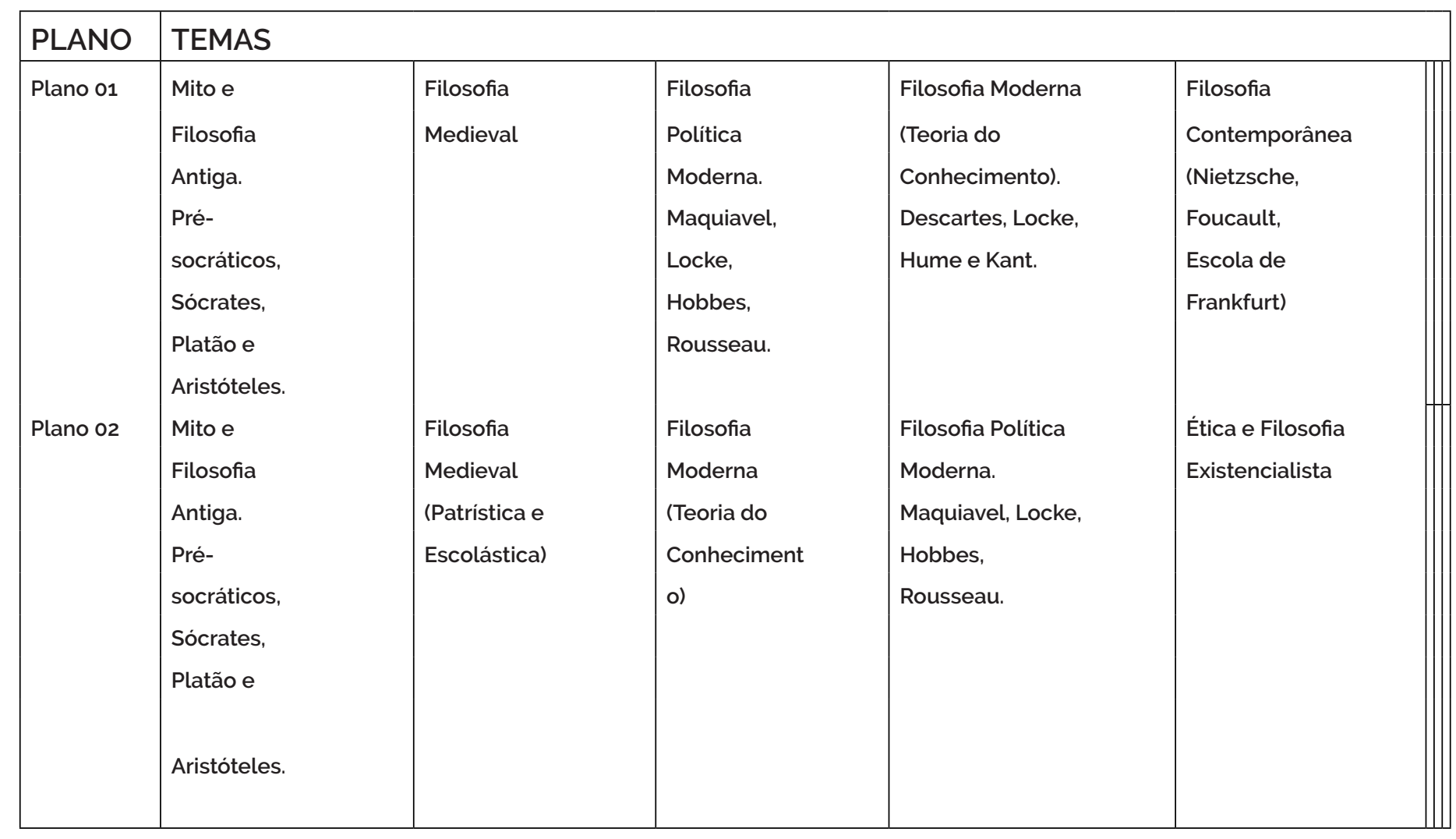



Danelon, M., \& Santos da Silva, M. (2019). Planejamento do ensino de Filosofia: entre a
normatividade e a prática pedagógica. Cuestiones De Filosofia, 5(24). 145-170

\begin{tabular}{|c|c|c|c|c|c|c|c|c|}
\hline Plano 03 & $\begin{array}{l}\text { Mito e } \\
\text { Filosofia } \\
\text { Antiga. Pré- } \\
\text { socráticos, } \\
\text { Sócrates, } \\
\text { Platão e } \\
\text { Aristóteles. }\end{array}$ & $\begin{array}{l}\text { Filosofia } \\
\text { Medi- } \\
\text { eval } \\
\text { (Patrísti- } \\
\text { ca e Es- } \\
\text { colásti- } \\
\text { ca) }\end{array}$ & $\begin{array}{l}\text { Filosofia Politica } \\
\text { Moderna. Ma- } \\
\text { quiavel, Locke, } \\
\text { Hobbes, Rous- } \\
\text { seau. }\end{array}$ & $\begin{array}{l}\text { Filosofia } \\
\text { Moderna (T. } \\
\text { do Conheci- } \\
\text { mento). Des- } \\
\text { cartes, Locke, } \\
\text { Hume e Kant. }\end{array}$ & $\begin{array}{l}\text { Foucault, Ni- } \\
\text { etzsche e Shopen- } \\
\text { hauer }\end{array}$ & Sartre & & \\
\hline Plano 04 & $\begin{array}{l}\text { Mito e } \\
\text { Filosofia } \\
\text { Antiga. Pré- } \\
\text { socráticos, } \\
\text { Sócrates, } \\
\text { Platão e } \\
\text { Aristóteles. }\end{array}$ & $\begin{array}{l}\text { Filosofia } \\
\text { Medi- } \\
\text { eval } \\
\text { (Patristi- } \\
\text { ca e Es- } \\
\text { colásti- } \\
\text { ca) }\end{array}$ & $\begin{array}{l}\text { Filosofia Mod- } \\
\text { erna (Teoria do } \\
\text { Conheciment o). } \\
\\
\text { Descartes, Locke, } \\
\text { Hume e Kant. }\end{array}$ & $\begin{array}{l}\text { Filosofia } \\
\text { Moderna (T. } \\
\text { do Conheci- } \\
\text { mento). Des- } \\
\text { cartes, Locke, } \\
\text { Hume e Kant. }\end{array}$ & $\begin{array}{l}\text { Ética (Kant, } \\
\text { Nietzsche e } \\
\text { Sartre) }\end{array}$ & & & \\
\hline Plano 05 & $\begin{array}{l}\text { Mito e } \\
\text { Filosofia } \\
\text { Antiga. Pré- } \\
\text { socráticos, } \\
\text { Sócrates, } \\
\text { Platão e } \\
\text { Aristóteles. }\end{array}$ & $\begin{array}{l}\text { Filosofia } \\
\text { Medi- } \\
\text { eval } \\
\text { (Patristi- } \\
\text { ca e Es- } \\
\text { colásti- } \\
\text { ca) }\end{array}$ & $\begin{array}{l}\text { Filosofia Moderna } \\
\text { (Teoria do Conhe- } \\
\text { ciment } \\
\text { o) Descartes, } \\
\text { Locke, Hume e } \\
\text { Kant. }\end{array}$ & $\begin{array}{l}\text { Filosofia } \\
\text { Moderna } \\
\text { (Teoria do } \\
\text { Conhecimen- } \\
\text { to) Descartes, } \\
\text { Locke, Hume } \\
\text { e Kant. }\end{array}$ & $\begin{array}{l}\text { Ética } \\
\text { (Aristóteles e } \\
\text { Kant) }\end{array}$ & $\begin{array}{l}\mathrm{N} \text { i - } \\
\text { etzsche, } \\
\text { Foucault } \\
\text { e Sartre }\end{array}$ & & \\
\hline Plano 06 & $\begin{array}{l}\text { Mito e } \\
\text { Filosofia } \\
\text { Antiga. Pré- } \\
\text { socráticos, } \\
\text { Sócrates, } \\
\text { Platão e } \\
\text { Aristóteles. }\end{array}$ & $\begin{array}{l}\text { Filosofia } \\
\text { Medi- } \\
\text { eval } \\
\text { (Patristi- } \\
\text { ca e Es- } \\
\text { colásti- } \\
\text { ca) }\end{array}$ & $\begin{array}{l}\text { Filosofia Mod- } \\
\text { erna (Teoria do } \\
\text { Conheciment o) }\end{array}$ & $\begin{array}{l}\text { Filosofia } \\
\text { Moderna (T. } \\
\text { do Conheci- } \\
\text { mento) Des- } \\
\text { cartes, Locke, } \\
\text { Hume e Kant. }\end{array}$ & $\begin{array}{l}\text { Ética } \\
\text { (Aristóteles e } \\
\text { Kant) }\end{array}$ & $\begin{array}{l}\text { Sartre, } \\
\text { Ni- } \\
\text { etzsche, } \\
\text { Foucault } \\
\text { e Es- } \\
\text { cola de } \\
\text { Frankfurt }\end{array}$ & & \\
\hline Plano 07 & $\begin{array}{l}\text { Mito e Filo- } \\
\text { sofia Antiga } \\
\text { Pré-soc- } \\
\text { ráticos, } \\
\text { Sócrates, } \\
\text { Platão e } \\
\text { Aristóteles. }\end{array}$ & $\begin{array}{l}\text { Filosofia } \\
\text { Medi- } \\
\text { eval } \\
\text { (Patristi- } \\
\text { ca e Es- } \\
\text { colásti- } \\
\text { ca) }\end{array}$ & $\begin{array}{l}\text { Filosofia Mod- } \\
\text { erna (Teoria do } \\
\text { Conheciment o) }\end{array}$ & $\begin{array}{l}\text { Filosofia } \\
\text { Moderna (Te- } \\
\text { oria do Con- } \\
\text { hecimento) }\end{array}$ & $\begin{array}{l}\text { Filosofia Contem- } \\
\text { porânea }\end{array}$ & & & \\
\hline Plano 08 & $\begin{array}{l}\text { Mito e Filo- } \\
\text { sofia Antiga } \\
\text { Pré-soc- } \\
\text { ráticos, } \\
\text { Sócrates, } \\
\text { Platão e } \\
\text { Aristóteles } \\
\text { e Filosofia } \\
\text { Helenista. }\end{array}$ & $\begin{array}{l}\text { Filosofia } \\
\text { Medi- } \\
\text { eval } \\
\text { (Patristi- } \\
\text { ca e Es- } \\
\text { colásti- } \\
\text { ca) }\end{array}$ & $\begin{array}{l}\text { Filosofia Politica } \\
\text { Moderna. Ma- } \\
\text { quiavel, Locke, } \\
\text { Hobbes, Rous- } \\
\text { seau. }\end{array}$ & $\begin{array}{l}\text { Filosofia } \\
\text { Moderna } \\
\text { (Teoria do } \\
\text { Conhecimen- } \\
\text { to). Descartes, } \\
\text { Locke, Hume } \\
\text { e Kant. }\end{array}$ & $\begin{array}{l}\text { Existencialismo } \\
\text { (Kierkegaard) }\end{array}$ & & & \\
\hline Plano 09 & $\begin{array}{l}\text { Mito e } \\
\text { Filosofia } \\
\text { Antiga. Pré- } \\
\text { socráticos, } \\
\text { Sócrates, } \\
\text { Platão e } \\
\text { Aristóteles. }\end{array}$ & $\begin{array}{l}\text { Filosofia } \\
\text { Medi- } \\
\text { eval } \\
\text { (Patristi- } \\
\text { ca e Es- } \\
\text { colásti- } \\
\text { ca) }\end{array}$ & $\begin{array}{l}\text { Filosofia Politica } \\
\text { Moderna Ma- } \\
\text { quiavel, Locke, } \\
\text { Hobbes, Rous- } \\
\text { seau. }\end{array}$ & $\begin{array}{l}\text { Filosofia } \\
\text { Moderna (T. } \\
\text { do Conheci- } \\
\text { mento). Des- } \\
\text { cartes, Locke, } \\
\text { Hume e Kant. }\end{array}$ & $\begin{array}{l}\text { Existencialismo } \\
\text { (Kierkegaard) }\end{array}$ & & & \\
\hline Plano 10 & Ética & Política & Democracia & $\begin{array}{l}\text { Filosofia Soc- } \\
\text { rática }\end{array}$ & $\begin{array}{l}\text { Ética em } \\
\text { Espinoza }\end{array}$ & $\begin{array}{l}\text { Ética } \\
\text { em } \\
\text { Peter } \\
\text { Singer }\end{array}$ & $\begin{array}{l}\text { Filo- } \\
\text { sofia } \\
\text { Afri- } \\
\text { cana }\end{array}$ & $\begin{array}{l}\text { Ética } \\
\text { e } \\
\text { direito }\end{array}$ \\
\hline
\end{tabular}


Como exposto, os planos de ensino de filosofia analisados, em suas referências, citam, quase na totalidade, o CBC/Filosofia. Na maior parte dos mesmos, são também referenciadas as ONC/Filosofia. As Diretrizes Gerais/UFU, por seu turno, nas referências, não figuram em nenhum dos planos.

Quando mencionadas, habilidades, competências e objetivos, as Orientações Curriculares eoCurrículo Básico Comum sãoigualmente referenciados textualmente. O mesmo, entretanto, uma vez mais, não acontece em relação às Diretrizes Gerais.

No tocante à abordagem adotada (histórica ${ }^{8}$, temáticas ${ }^{9}$ ou problematizante ${ }^{10}$ ), notase, quanto à forma, o predomínio da utilização da estrutura postulada pelo Currículo Básico Comum (temático). A despeito de variantes, $80 \%$ (oitenta por cento) dos planos analisados organizam-se em: I- eixos temáticos, II- temas, III- tópicos. Com efeito, estes se fazem acompanhados de uma lista de conteúdos que, invariavelmente, perfazem o percurso histórico da filosofia ocidental, da Grécia Antiga ao mundo contemporâneo, à maneira do que estabelecem as Diretrizes Gerais/UFU e, ainda que sutilmente, das OCN/Filosofia.

Há uma clara apropriação da estrutura do CBC/Filosofia (temática a partir de eixos). Contudo, organizam-se tais temas de modo a possibilitar uma espécie de contínuo histórico linear. São abordados os temas mais pertinentes ou conhecidos de cada periodo da história do pensamento. $O$ que faz com que, de alguma forma, à maneira do que ocorre com as OCN/Filosofia, o CBC/Filosofia se adapte à História da Filosofia.

Este fenômeno pode, pois, corroborar a ideia de que a história da filosofia, nos planejamentos docentes, seria a fonte da abordagem de temas filosóficos ou desvelar a intenção de que a história da filosofia, de alguma forma, caiba em uma estrutura

8 Consiste na apresentação da história do pensamento filosófico mormente, o ocidental. (ALMEIDA Jr, 2011; FELÍCIO, 2011).

9 É aquela na qual o ensino de filosofia ocorre, como o próprio nome evidencia, através de temas filosóficos, tais como: Liberdade, Justiça, Verdade, Bem, Conhecimento (ALMEIDA Jr, 2011; FELÍCIO, 2011).

10 É aquela que parte de problemas filosóficos como, por exemplo, a origem do conhecimento e a existência do mal, em diálogo com a tradição filosófica e a produção de conceitos (DELEUZE E GUATARI, 1992) 
de planejamento oficial, preestabelecida por um ou mais documentos reguladores. Documentos, estes, que, ainda que expressamente não o sejam, exerceriam, pois, em relação aos professores, influência de caráter "normativo". O mesmo não ocorre com as Diretrizes Gerais/Filosofia, apesar de seus conteúdos serem contemplados na maioria dos planos.

Em suma, a estrutura dos planejamentos, é concebida, majoritariamente, a partir do modelo postulado pelo $\mathrm{CBC} /$ Filosofia (temático a partir de eixos). Contudo, a abordagem e a seleção de conteúdos são organizadas em uma sequência cronológica, linear, histórica. São mencionados e contemplados temas das OCN/ Filosofia. E, embora não sejam mencionados, estão presentes na quase totalidade dos planos, os conteúdos selecionados para o Vestibular da Universidade Federal de Uberlândia.

Conforme os quadros antepostos, nenhum dos 3 (três) documentos se constitui na referência exclusiva ou é totalmente negligenciado no processo de elaboração dos planos analisados. Como citação direta, na estrutura ou na organização dos conteúdos, os documentos figuram amalgamados em todos os planejamentos, ora predominando este, ora aquele.

\section{4-) Algumas conclusões}

Compreendemos que a expressão da complexidade do trabalho do professor de filosofia não pode ser depreendida apenas a partir da análise textual de seus planos de ensino ou planejamentos anuais. Não se trata, outrossim, de comparar hierarquicamente tais planos. A questão central que se coloca é em relação à influência dos documentos regulatórios ou orientadores do ensino de filosofia na atividade de planejamento dos docentes em filosofia, especialmente, no tocante ao processo de seleção de conteúdos e no modelo de abordagem adotado.

O professor de filosofia, especificamente, em sua atividade profissional, tem a influência de diferentes projetos materializados pelos documentos oficiais, além de demandas diversas da sociedade e da escola; haja vista que o planejamento educacionalé, nas diferentes circunstâncias, um instrumento de política educacional, isto é, a forma pela qual se busca implementar determinada política preconizada para a educação (SAVIANI, 2007, p. 177). 
Para Japiassu (1997), o ensino de filosofia sofre com um processo de separação entre estudos literários e científicos descrito pelo autor em termos de uma "partilha brutal e desastrosa". Propomos, por conseguinte, que tal processo de fragmentação se estenda também aos postulados dos diferentes documentos orientadores e/ ou normativos atinentes ao ensino de filosofia no Brasil, notadamente, para este estudo, nas escolas da Superintendência Regional de Ensino de Uberlândia-MG.

No contexto atual, o professor de filosofia se vê diante de diferentes marcos orientadores e reguladores provenientes de distintos documentos, além de demandas diversas emanadas da escola e da sociedade ${ }^{11}$, como, por exemplo, a preparação dos estudantes para os processos seletivos de acesso ao ensino superior. Destarte, sua tarefa, antes de tudo, consistiria, em meio a todas estas referências, segundo Paviani (2002), em distinguir o que é essencial e o que é secundário no ensino de filosofia. Posto que planejar é fazer escolhas e estas não são ingênuas ou neutras.

Não se trata de tarefa fácil. Os documentos reguladores são referenciais importantes, mas podem se transformar em obste ao trabalho docente na medida em que não sejam apropriados critica, reflexiva e criativamente.

As Orientações Curriculares Nacionais de Filosofia do Ministério da Educação, o Currículo Básico Comum de Filosofia da Secretaria de Estado de Educação de Minas Gerais e as Diretrizes Gerais de Filosofia da Universidade Federal de Uberlândia formam um conjunto de documentos que balizam a prática do professor de Filosofia. Emerge o problema quando o professor assume um desses documentos enquanto diretriz de seu trabalho pedagógico e, também, quando elabora critérios para assumir determinado documento como diretriz de seu trabalho pedagógico. Se num passado próximo o professor carecia de referenciais e diretrizes que the auxiliasse em sua prática, a realidade atual é de excesso de documentos balizadores do trabalho pedagógico do professor. O professor de Filosofia do ensino médio de Uberlândia, por exemplo, pode elaborar seu plano de trabalho para a disciplina de Filosofia a partir de um desses três documentos, assumindo-o como referencial, ou pode selecionar partes dos documentos, misturando-os ecleticamente em seu plano de ensino. Mesmo assim, perguntamos: porque balizar-se por um determinado

11 A Lei de Diretrizes e Bases da Educação, Lei 9304/96 estabelece com objetivos da Educação Básica: a preparação para cidadania, a continuidade dos estudos e o mundo do trabalho. 
documento? Qual critério para descartar os demais? Apenas a predileção pessoal do professor? Ou o projeto político pedagógico da escola? O problema fica um pouco mais complexo na medida em que se constatar uma simetria entre os conteúdos propostos nos documentos e as avaliações preparadas e aplicadas pelas instituições de origem dos documentos ${ }^{12}$. No caso das provas de Filosofia nos processos seletivos de ingresso no ensino superior da Universidade Federal de Uberlândia há de fato uma simetria umbilical entre os conteúdos das Diretrizes Gerais de Filosofia/UFU e as questões de Filosofia solicitadas nas provas de Filosofia dos processos seletivos desta universidade.

No caso das Diretrizes Gerais de Filosofia/UFU, por determinar o conteúdo de Filosofia nas provas do processo seletivo para o ingresso no ensino superior da Universidade Federal de Uberlândia, acaba, concretamente, definindo o que o professor de Filosofia deve ensinar em sala de aula, uma vez que há interesses (da escola, dos pais dos alunos e do próprio professor) de que o aluno seja aprovado no processo seletivo, num claro exemplo de interferência da universidade sobre o currículo do ensino médio, como é possivel ser aferido nos quadros antepostos. $O$ mesmo ocorre no Exame Nacional do Ensino Médio (ENEM) ${ }^{13}$, certame organizado pelo Ministério da Educação (MEC), que se constitui no maior processo seletivo de ingresso no ensino superior público do Brasil. As questões de Filosofia que compõem o ENEM são produzidas a partir dos conteúdos de Filosofia presentes nas Orientações Curriculares Nacionais de Filosofia, o que torna praticamente obrigatório ao professor de filosofia atender, em seu plano de ensino, os conteúdos de filosofia estipulados nas Orientações Curriculares Nacionais, o que podemos observar nos planos analisados. Conforme os Quadro I e II, em um dos planos, as $\mathrm{OCN}$ é o documento predominante. Metade dos planos citam diretamente as $\mathrm{OCN}$ e, na seleção dos conteúdos, os temas postulados nas orientações são também, parcialmente contemplados ${ }^{14}$.

12 Essa temática da vivência do documento oficial no cotidiano do professor de Filosofia e da escola emerge como um problema fundamental em nossa pesquisa. Para, de fato, sabermos quais sentidos os documentos oficiais definem práticas do professor de Filosofia, nós elegemos três procedimentos: (i) análise dos conteúdos de Filosofia presentes nos documentos oficiais, cujo texto que aqui apresentamos se constitui num dos produtos dessa etapa da pesquisa; (ii) análise dos planos de ensino dos professores de Filosofia de Uberlândia; e (iii) análise das questões de Filosofia nas avaliações oficiais. Esclarecemos, por fim, que a terceira etapa será ainda iniciada.

13 O ENEM é criado em 1998 com vistas a avaliar o desempenho dos alunos, ao termo da educação básica. A partir de 2009, o Exame passa a ser também usado como forma de ingresso ao Ensino Superior.

14 Como já anunciado, esta questão da relação entre documentos, planos e avaliações será investigada com maior acuidade na próxima etapa deste estudo. 
Temos aqui um ponto de estrangulamento do trabalho do professor de filosofia, tanto porque ele constata que seu trabalho de ensinar conteúdos de filosofia está administrado por documentos oficiais, quanto porque ele constata a obrigatoriedade de assegurar, em seu plano de ensino, documentos distintos em suas concepções de filosofia, em sua tipologia de ensino de filosofia e, principalmente, em conteúdos de filosofia. Trata-se, conforme vimos, de um malabarismo pedagógico do professor de filosofia em contemplar em seu plano de ensino, conteúdos de filosofia tão distintos nos documentos. Em meio à fiscalização de órgãos reguladores da educação básica para que atendam determinados documentos normatizadores em seu plano de ensino e em meio às cobranças da sociedade civil para ensinar bem os conteúdos de filosofia solicitados nos processos seletivos, o professor de filosofia vai se equilibrando, como um funâmbulo, no tênue fio de sua prática pedagógica. $O$ problema que colocamos quando constatamos a administração do trabalho do professor de filosofia, em formato de documentos oficiais balizadores na elaboração dos planos de ensino de filosofia e a estreita e intrínseca relação desses documentos com os processos seletivos de ingresso no ensino superior e os planos de ensino, é pela definição do papel do professor de Filosofia. Cabe a ele operacionalizar uma proposta de ensino de Filosofia institucionalmente definida? É função do professor de Filosofia a execução desses conteúdos previamente pensados, planejados e institucionalmente definidos? Se há parâmetros e diretrizes, qual é, de fato, a abertura para que o professor, de forma autárquica, construa sua proposta pedagógica e defina os conteúdos de Filosofia? Essas interrogações nos remetem e inauguram a necessidade de se repensar a identidade do professor de Filosofia já que, em inúmeras situações, sua prática pedagógica fica restrita a um operador de conteúdos, conceitos e informações filosóficas, previamente planejadas por uma universidade e divulgadas em seus programas de conteúdos exigidos no processo seletivo, ou por uma secretaria de governo, numa nítida separação do trabalho entre aqueles que pensam e planejam e aqueles que fazem e executam.

Pelo fato desses documentos apresentarem uma concepção de ensino de Filosofia, definindo conteúdos e estabelecendo objetivos e, por se constituírem em documentos oficiais balizadores e norteadores da prática do professor de Filosofia, 
há, de fato, uma separação entre o trabalho de criar, pensar e planejar e o trabalho de executar. No instante em que o professor assume e adota como referencial de seu trabalho pedagógico uma concepção de ensino de Filosofia institucionalizada no aparato burocrático, ele se assume como um executor, um operacionalizador, um profissional do saber prático. $O$ professor de Filosofia se transforma num operário, naquele que é responsável pelos meios para a concretização dos fins antecipadamente planejados.

\section{Referências}

Almeida Júnior, José Benedito. Fundamentos teórico-metodológicos do ensino de filosofia. Educação em Revista, Marilia, v. 12, n1, p. 39-50, jan-jun, 2011.

Brasil. Lei 9394 de 20 de dezembro de 1996. Estabelece as Diretrizes e Bases da Educação Nacional.

Brasil. Lei 11684 de 2 de junho de 2008. Altera o art. 36 da Lei no 9.394, de 20 de dezembro de 1996, que estabelece as Diretrizes e Bases da Educação Nacional, para incluir a Filosofia e a Sociologia como disciplinas obrigatórias nos currículos do ensino médio.

Chizzotti, Antonio. Currículo por competência: ascensão de um novo paradigma curricular. Revista Educação e Filosofia, vol. 26, n 52, jul./dez. 2012, Uberlândia, EDUFU.

Conselho Nacional de Educação/Câmara de Educação Básica. Institui as Diretrizes Curriculares Nacionais para o Ensino Médio. Resolução CEB n 3 de 26 de junho de 1998.

Danelon, Marcio. Ensino de filosofia e currículo: um olhar crítico aos parâmetros curriculares nacionais. Cadernos de História da Educação, Uberlândia, v 09, $n^{\circ} 01$, pp. 109-129, jan-jun, 2010.

Deleuze, G; Guatari, F. O que é filosofia? Lisboa: Presença, 1992. Felício, C.B.F. Didática do ensino de filosofia. Goiânia: UFG.

Giordano, Rosely. Politicas da educação e sistemas filosóficos: a vontade da exclusão. Cadernos CEDES/Centro de Estudos Educação Sociedade. Vol.24, n. 64, p. 249-384, set./dez. 2004. São Paulo: Cortez; Campinas, Cedes.

Gonçalves, Tânia. $O$ ensino de filosofia na rede pública: a proposta curricular do Estado de São Paulo. In: GOTO, Roberto \& GALLO, Silvio (orgs) Da filosofia como 
disciplina. São Paulo: Edições Loyola, 2011.

Goodson, Ivor. Currículo: teoria e história. Petrópolis: Vozes, 1995.

Kohan, Walter \& WAKSMAN, Vera. Filosofia para crianças na prática escolar.

Petrópolis: Editora Vozes, 2001.p. 85.

Lipman, Matthew e outros. A Filosofia na sala de aula. São Paulo: Nova Alexandria, 1994.

Minas Gerais. Filosofia. Proposta curricular. Belo Horizonte: Secretaria de Estado de Educação, s/d.

Ministério da Educação/Secretaria de Educação Básica. Parâmetros Curriculares Nacionais - Ensino Médio - Ciências Humanas e suas tecnologias. - Brasília, Ministério da Educação, Secretaria de Educação Básica, 2000.

Ministério da Educação/Secretaria de Educação Básica. Ciências Humanas e suas tecnologias. (Orientações Curriculares para o Ensino Médio, volume 3). Ministério da Educação, Secretaria de Educação Básica, Brasilia, 2008. 133p.

Murcho, D. A natureza da filosofia e seu ensino. Educação. UFSM: Santa Maria, v. $27-n^{\circ} 02,2002$.

Saviani, D. Da nova LDB ao FUNDEB: por outra política educacional. Campinas- SP: Autores associados, 2007 (Coleção Educação Contemporânea)

Silva, Tomaz Tadeu \& MOREIRA, Antonio Flávio. Currículo, cultura e sociedade. São Paulo: Cortez Editora, 1995.

Vasconcellos, Celso dos S. Planejamento: projeto de ensinoaprendizagem e projeto político-pedagógico. 10 edição. São Paulo: Libertad, 2002

Lipman, Matthew e outros. A Filosofia na sala de aula. São Paulo: Nova Alexandria, 1994. 